\title{
BMJ Open Trends in the co-use of alcohol and tobacco among Japanese adolescents: periodical nationwide cross-sectional surveys 1996-2017
}

Maya Fujii (D) , ${ }^{1}$ Yuki Kuwabara (D) , ${ }^{1}$ Aya Kinjo (D) , ${ }^{1}$ Aya Imamoto, ${ }^{1,2}$ Maki Jike, ${ }^{3}$ Yuichiro Otsuka, ${ }^{4}$ Osamu Itani (D) , ${ }^{4}$ Yoshitaka Kaneita, ${ }^{4}$ Ruriko Minobe, ${ }^{5}$ Hitoshi Maesato, ${ }^{5}$ Susumu Higuchi, ${ }^{5}$ Hisashi Yoshimoto, ${ }^{6}$ Hideyuki Kanda, ${ }^{7}$ Yoneatsu Osaki (D) ${ }^{1}$
To cite: Fujii M, Kuwabara Y, Kinjo A, et al. Trends in the co-use of alcohol and tobacco among Japanese adolescents: periodical nationwide cross-sectional surveys 1996-2017. BMJ Open 2021;11:e045063. doi:10.1136/ bmjopen-2020-045063

- Prepublication history and additional supplemental material for this paper are available online. To view these files, please visit the journal online (http://dx.doi.org/10.1136/ bmjopen-2020-045063).

Received 21 September 2020 Accepted 13 July 2021

A) Check for updates

(c) Author(s) (or their employer(s)) 2021. Re-use permitted under CC BY-NC. No commercial re-use. See rights and permissions. Published by BMJ.

For numbered affiliations see end of article.

Correspondence to Dr Maya Fujii; maya15@live.jp

\section{ABSTRACT}

Objectives This study aimed to assess trends in the prevalence of alcohol use depending on smoking behaviours and that of smoking depending on drinking behaviours among Japanese adolescents.

Design This was a retrospective study using Japanese school-based nationwide surveys conducted between 1996 and 2017.

Setting Surveyed schools, both junior and senior high schools, considered representative of the entire Japanese population, were sampled randomly.

Participants We enrolled 11 584-64 152 students from 179 to 103 schools yearly. They completed a self-reported and anonymous questionnaire on smoking and drinking behaviour. Results Since 1996, the prevalence of alcohol use and smoking among adolescents decreased in each survey $(p<0.01)$. The prevalence of alcohol use in the non-smokers group was $29.0 \%$ in 1996 and $4.0 \%$ in 2017 , and in the smokers group, it was $73.3 \%$ in 1996 and $57.4 \%$ in 2017 . The reduction rate (the difference in prevalence between 1996 and 2017 divided by the prevalence in 1996) was 0.86 in the non-smokers group and 0.22 in the smokers group. The prevalence of smoking in the non-drinkers group was $6.7 \%$ in 1996 and $0.7 \%$ in 2017 , while that in the drinkers group was $32.5 \%$ in 1996 and $18.9 \%$ in 2017 . The reduction rate was 0.90 in the non-drinkers group and 0.42 in the drinkers group. Therefore, downward trends differed among the groups. In a subanalysis of senior high school students, we divided students into three groups according to their intention to pursue further education. Between 1996 and 2017, there was a consistent difference in the prevalence of alcohol use and smoking among these groups.

Conclusions Alcohol use and smoking among Japanese adolescents seem to have reduced. However, certain groups showed poor improvements, and health risk behaviour disparity exists, which may widen further. We need to focus on high-risk groups and implement appropriate measures or interventions accordingly.

\section{INTRODUCTION}

Smoking causes approximately eight million deaths worldwide annually, and the
Strengths and limitations of this study

- The data were collected from periodical, nationwide large-sample surveys on Japanese adolescents between 1996 and 2017, and the study contained a large sample size ( $n=11584-64152$ per year).

- This study focused on the co-use of alcohol and tobacco and analysed respective trends in the subgroups.

- Due to ethical concerns and inconvenience, school response rates were not as high as expected; however, the student response rate was consistent.

- Due to the ethical concerns, we did not ask students about their social and economic status and instead, analysed the trends by the students' intention to pursue further education.

- The study used a self-reporting questionnaire; hence, further studies to examine the accuracy of these findings are required.

harmful use of alcohol results in approximately three million deaths. ${ }^{12}$ Smoking and alcohol consumption usually start during adolescence, leading to detrimental consequences which include an epidemic of noncommunicable diseases in adulthood. Health risk behaviours (HRBs) are shaped by social, economic and cultural forces, and are major determinants of ill health and health-related inequalities through the course of life. ${ }^{3-5}$ Therefore, adolescence is the key period for controlling HRBs. Some studies have identified alcohol consumption, smoking, drug use and risky sexual behaviours as risk behaviour clusters, ${ }^{6-9}$ and socioeconomic status as a strong predictor of engaging in multiplerisk behaviours. ${ }^{10}$ Since 1996 , our research group has been monitoring alcohol use and smoking among adolescents in Japan. According to previous studies, the prevalence 
of alcohol use and smoking among adolescents in Japan has continued to decline and is reported to be lower than that in European countries and the USA. ${ }^{11}{ }^{12}$ Researchers have reported differences in the smoking and drinking behaviour depending on the characteristics of the adolescent group. For instance, socioeconomic backgrounds have a profound effect on the transition period of nonsmokers becoming daily smokers such that poor socioeconomic backgrounds caused the shortest transition period of non-smokers becoming smokers in France. ${ }^{13}$ Higher educational aspiration was negatively associated with alcohol use in Finland, ${ }^{14}$ and adolescents who were not in school were inclined to smoke in China. ${ }^{15}$ Moreover, some studies have reported on the positive relation between alcohol consumption and health inequality, and higher rates of morbidity and mortality among adults with a lower socioeconomic status. ${ }^{16-19}$ In Japan, despite the reduction in alcohol use and smoking among Japanese adolescents, it has not reached the goal of zero prevalence, as established by the Japanese government. Furthermore, because health inequalities and social disparities are the current public health issues in Japan, ${ }^{20}$ there may be groups of adolescents among whom smoking and alcohol use has not reduced. Therefore, it is important to examine whether an HRB disparity exists among Japanese adolescents. Very few studies have focused on the co-use of alcohol and tobacco and analysed trends in subgroups. Hence, we focused on this gap in existing research and hypothesised that some groups may have certain characteristics that demonstrate a slow rate of improvement in reducing alcohol use and smoking. To further lower alcohol use and smoking among adolescents, it is essential to evaluate these groups and implement relevant interventions. Incidentally, drug use among adolescents in Japan is not a major problem; the prevalence rate of drug use among teenagers was $0 \%$ in $2015 .{ }^{21}$ Therefore, this study aimed to evaluate the nationwide prevalence of smoking and alcohol use, as these were the two main substance-abuse problems and have been investigated as HRBs among Japanese adolescents.

\section{METHODS}

\section{Study population}

This was a cross-sectional random sampling survey that used single-stage cluster sampling. ${ }^{22}$ The sampling was performed by dividing Japan into regional blocks and randomly selecting schools from each block. Using the national school directory, junior high schools and senior high schools throughout Japan were randomly extracted, and all students enrolled in the sampled schools were participants of the study. The number, selection rate and response rate of the schools in each survey are shown in online supplemental table 1 . The response rates of schools ranged between $49.0 \%$ and $79.8 \%$.

To test our hypothesis, the research population was divided into the following subgroups: smokers group/ non-smokers group, drinkers group/non-drinkers group and their intention to pursue further education fell under four categories: (1) senior high school graduation, (2) junior college (2-year college/vocational school), (3) college or higher educational degree (4-year or 6-year college/graduate school) and (4) unknown. Next, trends in the prevalence of alcohol use and smoking in each group were examined.

\section{Data collection}

Online supplemental figure 1 shows the flow chart of data collection in the study. We obtained the cooperation of the principals of all the schools and sent the survey forms to all the students. The teachers encouraged the students to respond voluntarily and honestly. The students were given anonymised questionnaires and envelopes. The completed questionnaires were placed in envelopes and sealed by the students themselves, and these envelopes were collected by the teachers and returned to our institute.

\section{Patient and public involvement}

No patients were involved in this study.

\section{Measures}

\section{Alcohol use and smoking}

Drinkers and smokers were defined as those who had consumed alcohol or smoked at least once during the past 30 days. The questionnaire focused on the students' experiences, frequency of alcohol use ('How many days in the past 30 days have you had alcohol?') and smoking ('How many days in the past 30 days have you smoked cigarettes?'), amount of alcohol use ('How much alcohol have you had on a drinking day?') and smoking ('How many cigarettes on average per day have you smoked in the past 30 days?').

To assess the frequency of alcohol use, seven options were provided: ' 0 days', ' $1-2$ days', ' $3-5$ days', ' $6-9$ days', '10-19 days', '20-29 days' or 'every day'. To assess the amount of alcohol use, seven options were provided: 'no glass', 'less than 1 glass (a little bit)', '1 glass', '2 glasses', '3-5 glasses', 'more than 6 glasses' or 'until I got drunk'.

In the 1996 and 2000 surveys, to assess smoking, seven options were provided: 'have not smoked in past 30 days', 'less than 1 cigarette per day', '1-4 cigarettes', '5-9 cigarettes', '10-14 cigarettes', '15-19 cigarettes' or 'more than 20 cigarettes'; in the 2004 to 2017 surveys, eight options were provided: 'have not smoked in past 30 days', 'less than 1 cigarette per day', ' 1 cigarette', '2-5 cigarettes', '6-10 cigarettes', '11-15 cigarettes', '16-20 cigarettes' or 'more than 21 cigarettes' (online supplemental file 1). It was only in the 2017 survey when the questions on cigarettes were divided into three categories: combustible cigarette, heat-not-burn tobacco and electronic cigarettes. Thus, in the 2017 survey, this analysis regarded combustible cigarette users as smokers.

\section{Intention to pursue further education}

We assessed the intention to pursue further education after graduating from school ('What is your intention 
after graduating from school? Choose the option closest to your current feelings.'). Seven options were provided: 'senior high school', 'vocational school', '2-year college', 'college', 'graduate school', 'started working' and 'unknown'.

\section{Data analysis}

The proportions and $95 \%$ CIs presented in the tables were calculated using a weighting method and based on onestage stratified cluster sampling. ${ }^{22}$ The proportions were adjusted for grade and sex using the number of junior high and senior high school students nationwide as a standard population, from the School Basic Survey conducted by the Ministry of Education, Science and Technology (2017). A Cochran-Armitage trend test was performed to clarify the linear trend in prevalence by year. A $p$ value $<0.05$ was considered statistically significant. All statistical analyses were performed using JMP Pro V.13 for Windows (SAS). Data of the participants that did not include information on sex, grade or age were regarded as discrepant data and excluded from the analysis. To measure the rate of change in the prevalence, we calculated the reduction rate using the following formula: reduction rate $=$ (prevalence in 1996 - prevalence in 2017) / prevalence in 1996.

\section{RESULTS}

The differences in the baseline characteristics of participating schools, students (sex and grade), alcohol use in the past 30 days and smoking in the past 30 days are presented in table 1. Between 1996 and 2017, the prevalence of alcohol use and smoking steadily decreased.

Online supplemental figures 2 and 3 show the change in prevalence of alcohol use from 1996 to 2012 between the 7 th and 11th grades and between the 8th and 12th grades in every 4-year survey and between the 7 th grade in 2012 and the 12th grade in 2017. Online supplemental figures 4 and 5 show the change in smoking prevalence in the same groups described in online supplemental figures 2 and 3. Both, the prevalence of alcohol use and that of smoking among the same grade, showed a reduction over time.

Table 2 shows the prevalence rates for alcohol use only, smoking only, no-use and co-use in the past 30 days between 1996 and 2017. In each survey, the prevalence of co-use among boys was higher than among girls, while a significant decrease was observed in each survey among both boys and girls $(\mathrm{p}<0.01)$. Accordingly, in each survey, the prevalence of no-use among girls was higher than that among boys and was significantly increased in each survey among both boys and girls $(\mathrm{p}<0.01)$. In 2017, almost all the participants recorded no-use (boys $93.3 \%$, 95\% CI: $93.5 \%$ to $93.0 \%$; girls $95.0 \%$, $95 \%$ CI: $95.2 \%$ to $94.8 \%$ ). The prevalence of smoking only among boys was higher than that among girls, and it decreased in each survey among both boys and girls $(\mathrm{p}<0.01)$. Conversely, between 1996 and 2012, the prevalence of alcohol use only among girls was higher than that among boys, while in 2017, it was lower than that among boys.

\begin{tabular}{|c|c|c|c|c|c|c|}
\hline Year & 1996 & 2000 & 2004 & 2008 & 2012 & 2017 \\
\hline & $(n=115814)$ & $(n=106297)$ & $(n=102451)$ & $(n=95680)$ & $(n=100050)$ & $(n=64152)$ \\
\hline No of participants & n (\%) & n (\%) & n (\%) & n (\%) & n (\%) & n (\%) \\
\hline \multicolumn{7}{|l|}{ Sex } \\
\hline Boys & 57116 (49.3) & $54576(51.3)$ & 55998 (54.7) & $48525(50.7)$ & $51587(51.6)$ & $34582(53.9)$ \\
\hline Girls & $58698(50.7)$ & $51721(48.7)$ & 46453 (45.3) & $47155(49.3)$ & $48463(48.4)$ & $29570(46.1)$ \\
\hline \multicolumn{7}{|l|}{ School grade } \\
\hline \multicolumn{7}{|c|}{ Junior high school (12-15 years old) } \\
\hline Grade 7 & 14369 (12.4) & $15372(14.5)$ & 13146 (12.8) & $13302(13.9)$ & $13405(13.4)$ & $7384(11.5)$ \\
\hline Grade 8 & 14118 (12.2) & $15916(15.0)$ & $13079(12.8)$ & $13649(14.3)$ & $12884(12.9)$ & 7329 (11.4) \\
\hline Grade 9 & $14311(12.4)$ & $15958(15.0)$ & $13160(12.8)$ & 12925 (13.5) & 12205 (12.2) & 7415 (11.6) \\
\hline Unknown & $0(0.0)$ & $0(0.0)$ & $0(0.0)$ & $275(0.3)$ & $0(0.0)$ & $87(0.1)$ \\
\hline \multicolumn{7}{|c|}{ Senior high school (15-18 years old) } \\
\hline Grade 10 & $24696(21.3)$ & $21142(19.9)$ & 21815 (21.3) & $20157(21.1)$ & $21480(21.5)$ & $14201(22.1)$ \\
\hline Grade 11 & $25416(21.9)$ & $19600(18.4)$ & $21530(21.0)$ & $18328(19.2)$ & $20026(20.0)$ & $14212(22.2)$ \\
\hline Grade 12 & $22904(19.8)$ & $18309(17.2)$ & $19721(19.2)$ & $16785(17.5)$ & $20050(20.0)$ & $13404(20.9)$ \\
\hline Unknown & $0(0.0)$ & $0(0.0)$ & $0(0.0)$ & $259(0.3)$ & $0(0.0)$ & $120(0.2)$ \\
\hline \multicolumn{7}{|c|}{ Alcohol use/smoking in the past 30 days } \\
\hline Alcohol use & $44545(38.7)$ & 39497 (37.4) & 30233 (29.7) & $16110(16.9)$ & $12034(12.1)$ & $3584(5.6)$ \\
\hline Smoking & 20070 (17.9) & $16237(15.7)$ & $9614(9.5)$ & $4966(5.2)$ & $2851(2.9)$ & $1183(1.8)$ \\
\hline
\end{tabular}


Table 2 Prevalence of alcohol use and/or smoking among Japanese adolescents (aged 12-18 years) between 1996 and 2017 by sex

\begin{tabular}{|c|c|c|c|c|c|c|c|c|}
\hline \multirow[b]{2}{*}{ Year } & & 1996 & 2000 & 2004 & 2008 & 2012 & 2017 & \multirow[b]{2}{*}{ P value* } \\
\hline & & $\begin{array}{l}\% \\
95 \% \mathrm{Cl}\end{array}$ & $\begin{array}{l}\% \\
95 \% \mathrm{Cl}\end{array}$ & $\begin{array}{l}\% \\
95 \% \mathrm{Cl}\end{array}$ & $\begin{array}{l}\% \\
95 \% \mathrm{Cl}\end{array}$ & $\begin{array}{l}\% \\
95 \% \mathrm{Cl}\end{array}$ & $\begin{array}{l}\% \\
95 \% \mathrm{Cl}\end{array}$ & \\
\hline \multirow{2}{*}{ Boys } & Alcohol use only† & $\begin{array}{l}23.9 \\
(24.2 \text { to } 23.6)\end{array}$ & $\begin{array}{l}24.2 \\
\text { (24.6 to } 23.9 \text { ) }\end{array}$ & $\begin{array}{l}21.5 \\
\text { (21.8 to } 21.3)\end{array}$ & $\begin{array}{l}12.7 \\
\text { (12.8 to } 12.5)\end{array}$ & $\begin{array}{l}9.2 \\
(9.3 \text { to } 9.0)\end{array}$ & $\begin{array}{l}5.1 \\
(5.3 \text { to } 5.0)\end{array}$ & $<0.01$ \\
\hline & Co-use† & $\begin{array}{l}18.9 \\
\text { (19.5 to } 18.3)\end{array}$ & $\begin{array}{l}15.3 \\
\text { (15.7 to } 14.8)\end{array}$ & $\begin{array}{l}8.9 \\
(9.1 \text { to } 8.6)\end{array}$ & $\begin{array}{l}4.7 \\
(4.9 \text { to } 4.5)\end{array}$ & $\begin{array}{l}2.6 \\
(2.7 \text { to } 2.5)\end{array}$ & $\begin{array}{l}1.1 \\
(1.2 \text { to } 1.0)\end{array}$ & $<0.01$ \\
\hline \multirow[t]{2}{*}{ Girls } & No use $†$ & $\begin{array}{l}63.2 \\
(63.6 \text { to } 62.8)\end{array}$ & $\begin{array}{l}62.8 \\
\text { (63.3 to } 62.4)\end{array}$ & $\begin{array}{l}70.3 \\
\text { (70.7 to } 69.8)\end{array}$ & $\begin{array}{l}82.8 \\
\text { (83.1 to } 82.4)\end{array}$ & $\begin{array}{l}87.3 \\
(87.5 \text { to } 87.0)\end{array}$ & $\begin{array}{l}95.0 \\
(95.2 \text { to } 94.8)\end{array}$ & $<0.01$ \\
\hline & Co-use & $\begin{array}{l}7.8 \\
(8.0 \text { to } 7.6)\end{array}$ & $\begin{array}{l}7.7 \\
\text { (7.9 to } 7.5)\end{array}$ & $\begin{array}{l}5.1 \\
(5.1 \text { to } 4.8)\end{array}$ & $\begin{array}{l}2.5 \\
(2.6 \text { to } 2.4)\end{array}$ & $\begin{array}{l}1.4 \\
\text { (1.4 to } 1.3)\end{array}$ & $\begin{array}{l}0.6 \\
(0.6 \text { to } 0.5)\end{array}$ & $<0.01$ \\
\hline \multirow[t]{4}{*}{ Both } & No use $†$ & $\begin{array}{l}56.8 \\
(57.3 \text { to } 56.3)\end{array}$ & $\begin{array}{l}58.6 \\
(59.1 \text { to } 58.2)\end{array}$ & $\begin{array}{l}68.1 \\
(68.6 \text { to } 67.7)\end{array}$ & $\begin{array}{l}81.6 \\
\text { (81.9 to } 81.2)\end{array}$ & $\begin{array}{l}87.1 \\
\text { (87.3 to } 86.8)\end{array}$ & $\begin{array}{l}94.1 \\
\text { (94.3 to 93.9) }\end{array}$ & $<0.01$ \\
\hline & Alcohol use only† & $\begin{array}{l}25.3 \\
(25.5 \text { to } 25.1)\end{array}$ & $\begin{array}{l}25.6 \\
\text { (25.9 to } 25.4 \text { ) }\end{array}$ & $\begin{array}{l}22.4 \\
(22.6 \text { to } 22.1)\end{array}$ & $\begin{array}{l}13.2 \\
(13.4 \text { to } 13.0)\end{array}$ & $\begin{array}{l}10.1 \\
(10.2 \text { to } 9.9)\end{array}$ & $\begin{array}{l}4.7 \\
(4.9 \text { to } 4.6)\end{array}$ & $<0.01$ \\
\hline & Smoking only† & $\begin{array}{l}4.6 \\
(4.7 \text { to } 4.4)\end{array}$ & $\begin{array}{l}4.1 \\
(4.2 \text { to } 4.0)\end{array}$ & $\begin{array}{l}2.4 \\
\text { (2.5 to } 2.3 \text { ) }\end{array}$ & $\begin{array}{l}1.6 \\
(1.6 \text { to } 1.5)\end{array}$ & $\begin{array}{l}0.9 \\
(0.9 \text { to } 0.8)\end{array}$ & $\begin{array}{l}0.3 \\
(0.4 \text { to } 0.3)\end{array}$ & $<0.01$ \\
\hline & Co-use† & $\begin{array}{l}13.3 \\
(13.7 \text { to } 12.9)\end{array}$ & $\begin{array}{l}11.6 \\
\text { (11.9 to } 11.3 \text { ) }\end{array}$ & $\begin{array}{l}7.1 \\
\text { (7.3 to } 6.9)\end{array}$ & $\begin{array}{l}3.6 \\
\text { (3.8 to } 3.5 \text { ) }\end{array}$ & $\begin{array}{l}2.0 \\
(2.1 \text { to } 1.9)\end{array}$ & $\begin{array}{l}0.9 \\
(0.9 \text { to } 0.8)\end{array}$ & $<0.01$ \\
\hline
\end{tabular}

*Based on the Cochran-Armitage trend test.

†ln the past 30 days.

Online supplemental tables 2 and 3 show the prevalence of the amount of alcohol used among drinkers on a drinking day in three groups: 'less than 2 glasses', 'more than 3 glasses' and 'until I got drunk', and the prevalence of the average number of cigarettes smoked among smokers per day in two groups: 'less than 9 (10) cigarettes' and 'more than 10 (11) cigarettes'. Between 1996 and 2017, the prevalence of 'less than 2 glasses' among drinkers tended to increase in every survey. Between 2004 and 2017, the prevalence of 'more than 11 cigarettes' smokers did not increase considerably. Online supplemental tables 4 and 5 show the prevalence of the number of days alcohol was used in the past 30 days among drinkers in three groups: '1-9 days', '10-29 days' and 'every day', and the prevalence of the number of days when cigarettes were smoked in the past 30 days among smokers in three groups: '1-9 days', '10-29 days' and 'every day'. For drinkers, it did not change considerably, while among smokers, the number of every day smokers tended to decrease.

Figure 1 and table 3 show the prevalence of alcohol use among the non-smokers and smokers groups, and the prevalence of smoking among the non-drinkers and drinkers groups, adjusted for grade and sex. The prevalence of alcohol use in the non-smokers group was lower than that in the smokers group in each survey. In the non-smokers group, the prevalence rates did not change between the surveys of 1996 and 2000. However, in the surveys from 2004 to 2017, it decreased in each survey among both boys and girls. Conversely, it increased between 1996 and 2004 in the smokers group and subsequently decreased between 2004 and 2008 among both boys and girls. Among boys, it decreased in 2017, whereas among girls, it increased in 2012 and decreased in 2017. The reduction rates in the smokers group were lower than that in the non-smokers group; the reduction rate among girls in the smokers group was 0.19 , which was the lowest. Similarly, the prevalence of smoking was lower in the non-drinkers group than in the drinkers group. In the non-drinkers group, the prevalence of smoking decreased between 1996 and 2000 among boys, whereas it increased among girls. Between 2000 and 2017, it halved in each survey among both boys and girls. However, in the drinkers group, it decreased between 1996 and 2000 among boys, whereas it did not change among girls. Between 2000 and 2012, it decreased, and between 2012 and 2017, it increased slightly among boys and girls. Moreover, the reduction rates in the drinkers group were lower than that in the non-drinkers group. 

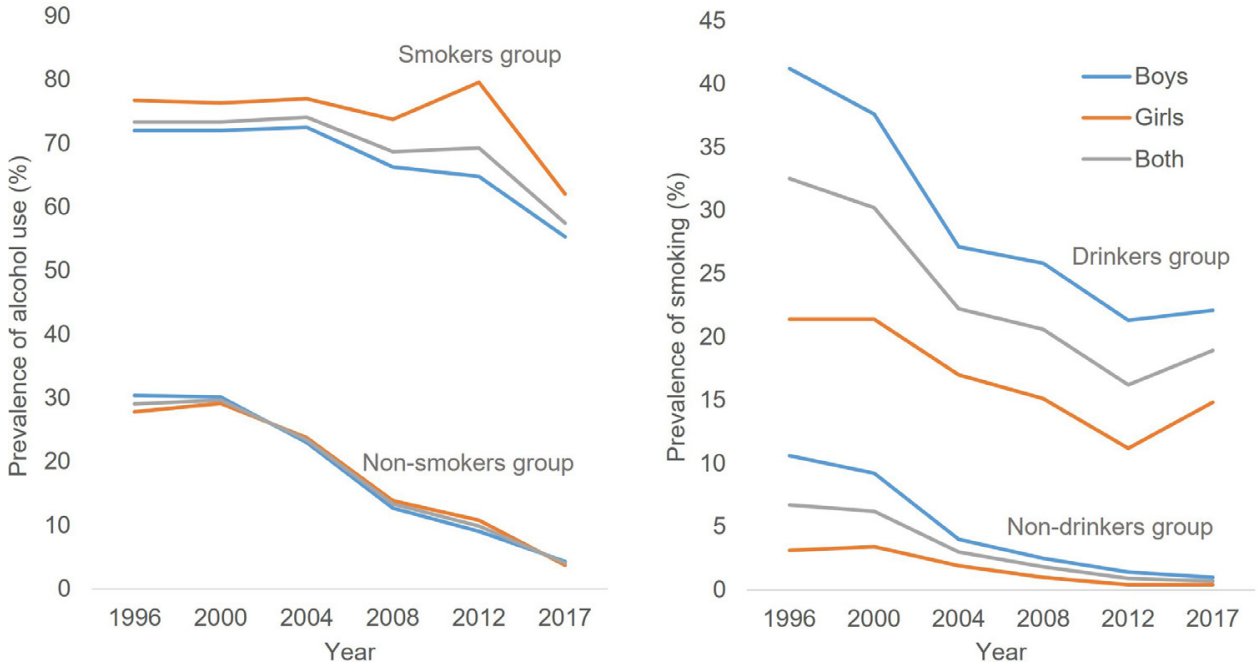

Figure 1 Prevalence of alcohol use depending on smoking and prevalence of smoking depending on alcohol use among Japanese adolescents (aged 12-18 years) between 1996 and 2017 by sex.

Table 4 shows the prevalence of alcohol use and smoking among senior high school students (aged 15-18 years) by the intention to pursue further education, adjusted for grade and sex. The prevalence of alcohol use decreased in each survey among the three groups, except for the junior college degree group between 1996 and 2000. The prevalence of smoking decreased in each survey among the three groups, except for the high school graduation group and college or the higher education degree group between 1996 and 2000. Both the prevalence of alcohol use and smoking in the college or higher educational degree groups were the lowest in each survey, with the reduction rate being the highest among the three groups.

\section{DISCUSSION}

In this study, we found a decrease in the prevalence of alcohol use and smoking among the representative sample groups of Japanese adolescents between 1996 and 2017. Moreover, this prevalence decreased to levels lower than those in the European countries ${ }^{23}$ and the USA. ${ }^{24}$ Japan and other countries have shown a declining trend in alcohol and tobacco use, ${ }^{23-26}$ which may have been due to the influence of the devaluation of alcohol and tobacco, as well as socioeconomic changes. In terms of alcohol, reports have indicated that the global reduction in drinking habits in youth may have been due to a change in the societal and economic devaluation of alcohol. ${ }^{27-29}$ Tobacco control activity may have influenced those smokers who found it easier to quit, while the remaining smokers were those who were less likely to stop smoking. ${ }^{30}{ }^{31}$ However, according to the results of this study, the prevalence of frequent users of alcohol and tobacco did not show an increase. The prevalence of alcohol use and smoking among Japanese adolescents seems to have improved, even if the goal of zero prevalence established by the Japanese government has not been reached. In this study, we hypothesised that some groups may have certain characteristics that demonstrate a slow rate of improvement in reducing alcohol use and smoking. To this end, we compared the trend of alcohol use by dividing the students into two groups: smokers and non-smokers, and similarly, the trend of smoking by creating two groups: drinkers and non-drinkers. Between 1996 and 2017, the prevalence of alcohol use in the smokers group was consistently higher than that in the non-smokers group, and the reduction rate in the smokers group was lower than that in the non-smokers group. In other words, the prevalence of alcohol use among smokers decreased at a rate slower than that among nonsmokers. Further, we compared the trend of smoking between the non-drinkers and drinkers groups and examined the overall trend in the prevalence of smoking. Between 1996 and 2017, the prevalence of smoking in the drinkers group was consistently higher than that in the non-drinkers group, and the reduction rate in the drinkers group was lower than that in the non-drinkers group. In other words, the prevalence of smoking in the drinkers group decreased at a rate slower than that in the non-drinkers group. These findings suggest that not only does an HRB disparity exist among Japanese adolescents, but also that it may be widening.

The trends in alcohol and tobacco use among the adults around adolescents may explain our results. Adolescent smoking behaviour is influenced by their parents, older brothers, older sisters and friends. ${ }^{32}$ In terms of their friends, the school environment influenced their alcohol use and smoking behaviour. ${ }^{33} 34$ Of the 153 schools that participated in the 1996 survey, the prevalence of alcohol use in every participating school ranged from $12.1 \%$ to $76.0 \%$, and that of smoking from $0.7 \%$ to $50.5 \%$. All the participating schools had at least one student who drank alcohol and smoked tobacco. Of the 103 schools that participated in the 2017 survey, the prevalence of alcohol use in every participating school ranged from $0 \%$ to $13.8 \%$ and that of smoking from $0 \%$ to $8.8 \%$. There were two schools $(1.9 \%)$ where no student 


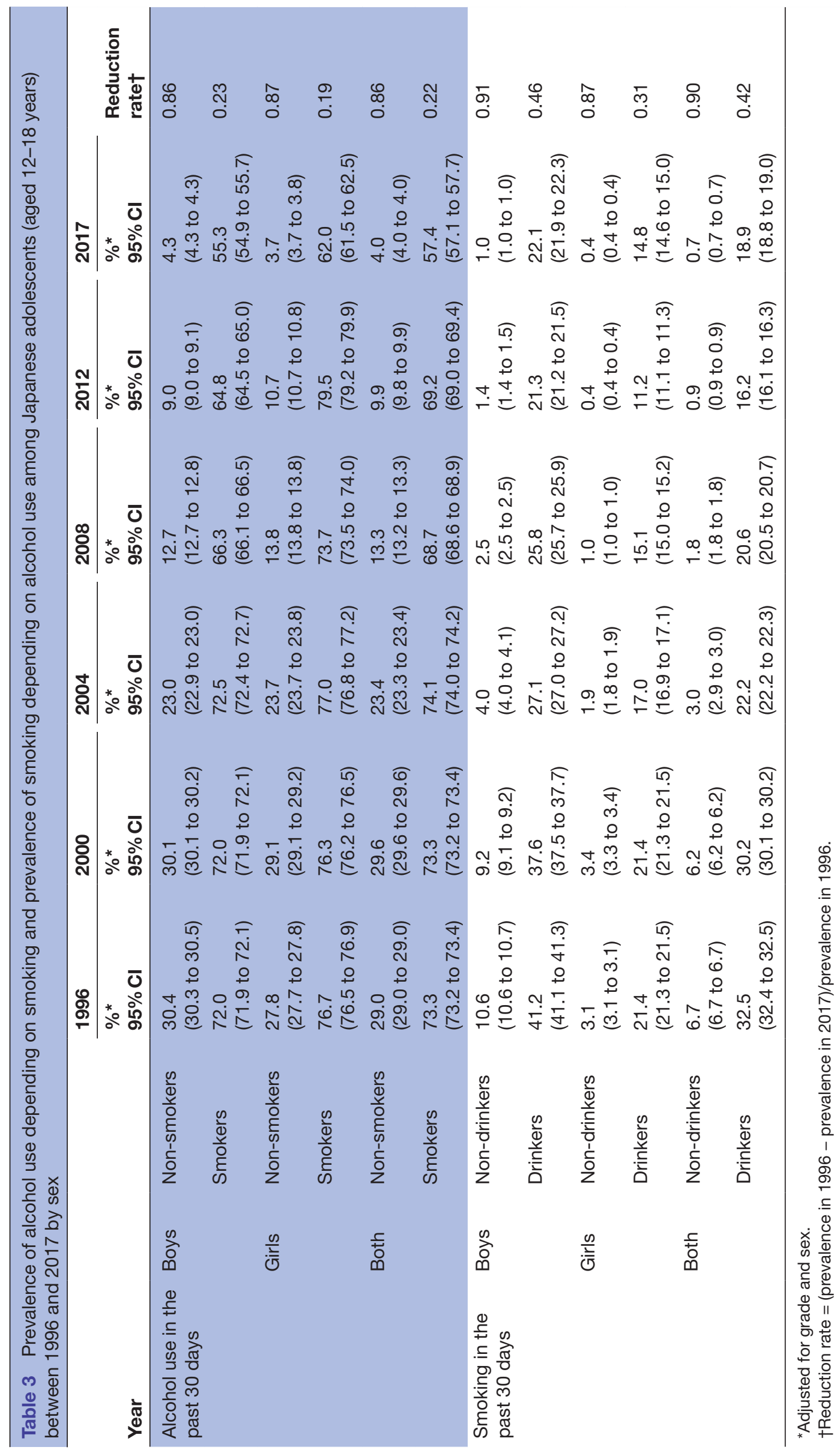


Table 4 Prevalence of alcohol use and smoking among Japanese senior high school students (aged 15-18 years) between 1996 and 2017 by the intention to pursue further education

\begin{tabular}{|c|c|c|c|c|c|c|c|}
\hline & 1996 & 2000 & 2004 & 2008 & 2012 & 2017 & \\
\hline Year & $\begin{array}{l}\% * \\
95 \% \mathrm{Cl}\end{array}$ & $\begin{array}{l}\% * \\
95 \% \mathrm{Cl}\end{array}$ & $\begin{array}{l}\% * \\
95 \% \mathrm{Cl}\end{array}$ & $\begin{array}{l}\% * \\
95 \% \mathrm{Cl}\end{array}$ & $\begin{array}{l}\% * \\
95 \% \mathrm{Cl}\end{array}$ & $\begin{array}{l}\% * \\
95 \% \mathrm{Cl}\end{array}$ & $\begin{array}{l}\text { Reduction } \\
\text { rate† }\end{array}$ \\
\hline \multicolumn{8}{|c|}{ Alcohol use in the past 30 days } \\
\hline $\begin{array}{l}\text { High school } \\
\text { graduation }\end{array}$ & $\begin{array}{l}52.7 \\
(52.6 \text { to } 52.9)\end{array}$ & $\begin{array}{l}53.1 \\
\text { (52.9 to } 53.2)\end{array}$ & $\begin{array}{l}43.7 \\
\text { (43.6 to } 43.9)\end{array}$ & $\begin{array}{l}29.2 \\
(29.0 \text { to } 29.3)\end{array}$ & $\begin{array}{l}19.9 \\
(19.8 \text { to } 20.0)\end{array}$ & $\begin{array}{l}9.4 \\
\text { (9.4 to } 9.5)\end{array}$ & 0.82 \\
\hline $\begin{array}{l}\text { College or higher } \\
\text { educational } \\
\text { degree }\end{array}$ & $\begin{array}{l}18.0 \\
(17.9 \text { to } 18.1)\end{array}$ & $\begin{array}{l}16.6 \\
(16.5 \text { to } 16.6)\end{array}$ & $\begin{array}{l}10.1 \\
\text { (10.1 to } 10.2)\end{array}$ & $\begin{array}{l}5.7 \\
(5.7 \text { to } 5.8)\end{array}$ & $\begin{array}{l}3.2 \\
\text { (3.1 to } 3.2 \text { ) }\end{array}$ & $\begin{array}{l}1.8 \\
\text { (1.8 to } 1.8)\end{array}$ & 0.90 \\
\hline \multicolumn{8}{|c|}{ Smoking in the past 30 days } \\
\hline $\begin{array}{l}\text { High school } \\
\text { graduation }\end{array}$ & $\begin{array}{l}36.8 \\
(36.7 \text { to } 36.9)\end{array}$ & $\begin{array}{l}37.7 \\
(37.5 \text { to } 37.8)\end{array}$ & $\begin{array}{l}23.7 \\
(23.6 \text { to } 23.8)\end{array}$ & $\begin{array}{l}15.5 \\
(15.4 \text { to } 15.7)\end{array}$ & $\begin{array}{l}7.6 \\
(7.5 \text { to } 7.6)\end{array}$ & $\begin{array}{l}4.0 \\
(3.9 \text { to } 4.0)\end{array}$ & 0.89 \\
\hline $\begin{array}{l}\text { College or higher } \\
\text { educational } \\
\text { degree }\end{array}$ & $\begin{array}{l}13.1 \\
(13.0 \text { to } 13.2)\end{array}$ & $\begin{array}{l}14.6 \\
(14.6 \text { to } 14.7)\end{array}$ & $\begin{array}{l}6.7 \\
(6.6 \text { to } 6.7)\end{array}$ & $\begin{array}{l}3.1 \\
(3.1 \text { to } 3.1)\end{array}$ & $\begin{array}{l}1.4 \\
(1.3 \text { to } 1.4)\end{array}$ & $\begin{array}{l}1.0 \\
(1.0 \text { to } 1.0)\end{array}$ & 0.92 \\
\hline
\end{tabular}

${ }^{\star}$ Adjusted for grade and sex.

†Reduction rate $=($ prevalence in 1996 - prevalence in 2017)/prevalence in 1996.

used alcohol in the past 30 days and 17 schools (16.5\%) where no student smoked tobacco in the past 30 days. Although the differences in prevalence between schools were reducing, they still existed. Adolescent drinking and smoking prevention efforts should include enhancing the collective efficacy of schools. In terms of their families, boys are influenced by their fathers and girls by their mothers. ${ }^{11}$ In Japan, the prevalence of smoking among adults was shown to have decreased annually among both men and women, ${ }^{35}$ which may have affected the change in smoking behaviour among adolescents. Adolescents' drinking behaviours are also related to their family and friends. In particular, an adolescent's drinking behaviour is more influenced by their mother's alcohol consumption pattern than those of other family members. ${ }^{12}$ In Japan, the prevalence of alcohol consumption among men has not increased significantly, whereas it has grown among women. ${ }^{35}$ This behaviour among women may affect their children's adolescent drinking behaviour. The prevalence of alcohol use among girls in the smokers group was consistently higher than that among boys in the same group, and the reduction rate was the lowest. A probable reason for these trends is that the prevalence of alcohol use in the parents' generation, especially in women, did not decrease, unlike that of smoking. Further, girls were influenced considerably by their mothers.

Additionally, the reduction rate in the prevalence of smoking in the drinkers and non-drinkers groups was higher than that of alcohol use in the smokers and nonsmokers groups. This may have been the result of the different political measures instituted against tobacco and alcohol use in Japan. Since the implementation of the tobacco tax in the country, tobacco and consumer taxes have increased several times. For example, the price of a pack of 20 of the most popular cigarette brands was $¥ 240$ (equivalent to US\$2) in 1996 . This increased to $¥ 250$ (4\% increase), ¥270 (8\% increase), ¥300 (11\% increase), $¥ 410$ ( $37 \%$ increase) and $¥ 420$ (2\% increase) in 1998, 2003, 2006, 2010 and 2014, respectively. Moreover, selfregulation of the tobacco industry from 1998 resulted in the regulation of tobacco commercials. An increase in the price of cigarettes and the regulation of tobacco commercials may, thus, have contributed to the decrease in the rate of smoking among adolescents. However, the prevalence of smoking among drinkers increased between 2012 and 2017. Further, the alcohol tax varied according to the type of alcohol; the tax on beer was stable between 1996 and 2017. Thus, the price of alcohol increased by only $2 \%-3 \%$ because of the consumer tax; the cheapest beer or alcopop was sold for less than US $\$ 1$. Before 2000, students could buy alcohol from supermarkets, convenience stores, and vending machines. In 2000, Japan enacted a revision of the Act to Prohibit Minors from using alcohol with a reinforcement of penalty for selling alcoholic beverages to minors. The law was revised again in 2001 to reinforce age confirmation by liquor distributors. After 2000, the number of alcohol vending machines also decreased due to the self-regulation of the alcohol industry. ${ }^{36}$ Therefore, the decrease in the prevalence of alcohol use among adolescents since 2000 may be attributed to the aforementioned policy. However, from 2004, a bigger decrease was shown among both 
the smokers and non-smokers groups, suggesting that although alcohol policies were changed in 2000, their effect was delayed as the policies were spread widely and slowly. Moreover, alcohol commercials remained unbanned. These policies had different effects on each subgroup. Increasing tobacco prices and deferring alcohol prices may have contributed to the differences in the reduction rates of the prevalence of alcohol use and smoking, respectively.

Our findings revealed that the trends in alcohol use and smoking differed between the non-smokers and smokers groups and between the non-drinkers and drinkers groups. These results can be partly explained by the social context of those substance users. Some Japanese researchers have reported an association between the social context and HRBs. For example, the prevalence of lifetime alcohol use and smoking was found to be much higher in adolescent youth detention centres in Japan than that outside such centres, ${ }^{21}$ schools and neighbourhood contexts were also found to be associated with adolescent drinking, ${ }^{33}$ and childhood poverty had a negative effect on adult HRBs. ${ }^{37}$ This study showed different trends in the prevalence of alcohol use and smoking in each subgroup, that is, the lifestyle of non-drinkers and non-smokers has become healthier, whereas that of drinkers and smokers has not changed, despite the decrease in the number of adolescent drinkers and smokers. Additionally, we observed that there were differences in the trends of the prevalence of alcohol use and that of smoking depending on the intentions of pursuing further education: the group that had the highest intention to pursue further academic studies had the greatest reduction rate; that is, students who had higher academic intentions showed a greater decrease in prevalence than those who had lower academic intentions. Student choices after graduating from senior high school influenced their future socioeconomic status and lifestyle. Some researchers have reported that HRBs, such as alcohol use and smoking, were associated with lower academic performance. ${ }^{38} 39$ This observation was consistent with our findings, where there were differences in the trends of prevalence of alcohol use, that of smoking and reduction rate depending on the intention to pursue further education. This implied that adolescent HRBs could be a driving factor in their life in the future. In the context of not widening the inequality gap, these results highlighted the importance of focusing on the high-risk groups that delay the reduction in the prevalence and develop appropriate strategies to intervene in such groups; for example, school-based interventions.

The strength of our study is that the data were collected from periodical, nationwide large-sample surveys. This methodology enabled us to minimise any sampling bias. ${ }^{22}$ Hence, the results of this study can potentially be generalised nationwide for Japanese adolescents. However, our study also had several limitations. First, the sample of the participants was possibly biased, since $30 \%-50 \%$ of the sampled schools did not respond to the surveys. Despite the efforts made by the research team, ethical concerns and inconvenience due to the need for elaborate explanations may have resulted in the lower rate of cooperation among schools. Specifically, the most pertinent ethical issue was the requirement to meet the criteria required for ethical approval. However, the characteristics of the schools that responded did not differ significantly from those of the non-responding schools. Since this tendency was consistent across the surveys, the trends in this study were interpreted easily. Second, although student questionnaires were anonymous and the students put them into private envelopes themselves, the distribution of the forms by class teachers may have influenced the results. Additionally, the explanatory document given to the class teachers explained that they had to ensure the students' privacy. Notwithstanding these limitations, it is important to continue conducting periodic nationwide surveys, even if some methodological problems persist.

\section{CONCLUSION}

Since 1996, the prevalence rates of drinking and smoking among Japanese adolescents have decreased. However, the trends were different between the non-drinkers and drinkers groups, and the non-smokers and smokers groups. In other words, not only does an HRB disparity exist among Japanese adolescents, but it may be widening. The results from the subanalysis indicated that students who had higher academic intentions presented a greater reduction in the prevalence of alcohol use and smoking, a trend associated with their future socioeconomic status. To further decrease the prevalence of alcohol use and smoking among adolescents, it is imperative to comprehensively adapt interventions, enlighten adults and parents, raise the prices of tobacco and alcohol, and regulate sale promotions. Furthermore, to not widen the inequality gap further, the results suggest that it is important to focus on the high-risk group that delays improvement, consider social contexts and develop an appropriate strategy to approach or intervene in this group.

\section{Author affiliations}

${ }^{1}$ Division of Environmental and Preventive Medicine, Department of Social Medicine, Faculty of Medicine, Tottori University, Yonago, Tottori, Japan

${ }^{2}$ Department of Pediatrics and Perinatology, Faculty of Medicine, Tottori University, Yonago, Tottori, Japan

${ }^{3}$ Department of Food Safety and Management, Faculty of Food and Health Sciences, Showa Women's University, Setagaya, Tokyo, Japan

${ }^{4}$ Division of Public Health, Department of Social Medicine, Nihon University School of Medicine, Itabashi, Tokyo, Japan

${ }^{5}$ National Hospital Organization Kurihama Medical and Addiction Center, Yokosuka, Kanagawa, Japan

${ }^{6}$ Department of Family Medicine, General Practice and Community Health, Faculty of Medicine, University of Tsukuba, Tsukuba, Ibaraki, Japan 
${ }^{7}$ Department of Public Health, Okayama University Graduate School of Medicine, Dentistry and Pharmaceutical Sciences, Okayama, Japan

\section{Twitter Osamu Itani @JIMARO_0710}

Acknowledgements We would like to thank Editage for English language editing. Contributors YOs, SH and YKa designed the study and devised its protocols. Ol, $\mathrm{YOt}, \mathrm{MJ}$ and $\mathrm{HY}$ reviewed the literature and helped summarising previous research studies. HK, AK, YKu, RM, HM and Al carried out statistical analyses. MF wrote the first draft of the manuscript. All authors read and approved the manuscript.

Funding This study was supported by a grant for Comprehensive Research on Lifestyle-Related Diseases, including cardiovascular diseases and diabetes mellitus, from the Ministry of Health and Welfare Health Science Research Fund in Japan (grant no. 29060801)

Disclaimer The funding body did not have any role in the design of the study; collection, analysis, and interpretation of data; or writing of the manuscript.

Competing interests None declared.

Patient consent for publication Not required.

Ethics approval The participants were older than 12 years of age. Before the survey, the school principals provided participant parents with the survey details. The parents were advised that they could refuse participation if they were reluctant to allow their children to take part in the survey. In other words, the parents were given the opportunity to opt their children out of the survey, if they were not comfortable with their participation. The students whose parents refused permission for their participation in the survey were not included. This survey and opt-out parental consent procedure were approved by the Ethics Review Committee of Tottori University Faculty of Medicine (reference no. 17A078).

Provenance and peer review Not commissioned; externally peer reviewed.

Data availability statement Not applicable.

Supplemental material This content has been supplied by the author(s). It has not been vetted by BMJ Publishing Group Limited (BMJ) and may not have been peer-reviewed. Any opinions or recommendations discussed are solely those of the author(s) and are not endorsed by BMJ. BMJ disclaims all liability and responsibility arising from any reliance placed on the content. Where the content includes any translated material, BMJ does not warrant the accuracy and reliability of the translations (including but not limited to local regulations, clinical guidelines, terminology, drug names and drug dosages), and is not responsible for any error and/or omissions arising from translation and adaptation or otherwise.

Open access This is an open access article distributed in accordance with the Creative Commons Attribution Non Commercial (CC BY-NC 4.0) license, which permits others to distribute, remix, adapt, build upon this work non-commercially, and license their derivative works on different terms, provided the original work is properly cited, appropriate credit is given, any changes made indicated, and the use is non-commercial. See: http://creativecommons.org/licenses/by-nc/4.0/.

\section{ORCID iDs}

Maya Fujii http://orcid.org/0000-0001-5474-7116

Yuki Kuwabara http://orcid.org/0000-0001-7164-6974

Aya Kinjo http://orcid.org/0000-0001-7099-5486

Osamu Itani http://orcid.org/0000-0002-8526-785X

Yoneatsu Osaki http://orcid.org/0000-0002-9846-4043

\section{REFERENCES}

1 World Health Organization. WHO report on global tobacco epidemic, 2019. Available: https://www.who.int/tobacco/global_report/en//

2 World Health Organization. Global status report on alcohol and health, 2018. Available: https://www.who.int/substance_abuse/ publications/global_alcohol_report/en/

3 Raphael D. Adolescence as a gateway to adult health outcomes. Maturitas 2013;75:137-41.

4 Mackenbach JP, Stirbu I, Roskam A-JR, et al. Socioeconomic inequalities in health in 22 European countries. $N$ Engl J Med 2008;358:2468-81.

5 Dick B, Ferguson BJ. Health for the world's adolescents: a second chance in the second decade. J Adolesc Health 2015;56:3-6.

6 Assanangkornchai S, Li J, McNeil E, et al. Clusters of alcohol and drug use and other health-risk behaviors among Thai secondary school students: a latent class analysis. BMC Public Health 2018;18:1272.

7 Akasaki M, Ploubidis GB, Dodgeon B, et al. The clustering of risk behaviours in adolescence and health consequences in middle age. $J$ Adolesc 2019;77:188-97.

8 Verhagen CE, Uitenbroek DG, Schreuders EJ, et al. Does a reduction in alcohol use by Dutch high school students relate to higher use of tobacco and cannabis? BMC Public Health 2015;15:821. oi:.

9 Daw J, Margolis R, Wright L. Emerging adulthood, emergent health lifestyles: sociodemographic determinants of trajectories of smoking, binge drinking, obesity, and sedentary behavior. J Health Soc Behav 2017;58:181-97.

10 Meader N, King K, Moe-Byrne T, et al. A systematic review on the clustering and co-occurrence of multiple risk behaviours. BMC Public Health 2016;16:1-9.

11 Osaki Y, Tanihata T, Ohida T, et al. Decrease in the prevalence of smoking among Japanese adolescents and its possible causes: periodic nationwide cross-sectional surveys. Environ Health Prev Med 2008;13:219-26.

12 Osaki Y, Tanihata T, Ohida T, et al. Decrease in the prevalence of adolescent alcohol use and its possible causes in Japan: periodical nationwide cross-sectional surveys. Alcohol Clin Exp Res 2009;33:247-54.

13 Janssen E, Nézet OL, Shah J. Increasing socioeconomic disparities in tobacco smoking decline among French adolescents (2000-2017). J Publ Health 2019;135:1-9.

14 Liu Y, Lintonen T, Tynjälä J, et al. Socioeconomic differences in the use of alcohol and drunkenness in adolescents: trends in the health behaviour in school-aged children study in Finland 1990-2014. Scand J Public Health 2018;46:102-11.

15 Chen L, Liu R, Pozhidaeva M, et al. Changes in the sociodemographic factors of tobacco and alcohol consumption in Chinese adolescents from 2004 to 2011. Int J Environ Res Public Health 2018;15:1211.

16 Mäkelä P, Keskimäki I, Koskinen S. What underlies the high alcohol related mortality of the disadvantaged: high morbidity or poor survival? J Epidemiol Community Health 2003;57:981-6.

17 Dietze PM, Jolley DJ, Chikritzhs TN, et al. Income inequality and alcohol attributable harm in Australia. BMC Public Health 2009;9:70.

18 Mäkelä P, Paljärvi T. Do consequences of a given pattern of drinking vary by socioeconomic status? A mortality and hospitalisation followup for alcohol-related causes of the Finnish drinking habits surveys. J Epidemiol Community Health 2008;62:728-33.

19 Probst C, Roerecke M, Behrendt S, et al. Socioeconomic differences in alcohol-attributable mortality compared with all-cause mortality: a systematic review and meta-analysis. Int J Epidemiol 2014;43:1314-27.

20 Ministry of Health, Labour and Welfare of Japan. Comprehensive survey of living conditions. Available: https://www.mhlw.go.jp/toukei/ saikin/hw/k-tyosa/k-tyosa16/dl/16.pdf

21 Shimane T. Nationwide general population survey on drug use in Japan, 2015. Available: https://www.ncnp.go.jp/nimh/yakubutsu/ report/pdf/2017_0522_2015EN_shimane2_k.pdf

22 Cochran WG. Sampling techniques, 3D ED: chapter 9A singlestage cluster sampling: clusters of unequal sizes. New York: Wiley, 1977: 249-73.

23 ESPAD Group. ESPAD Report 2019: Results from the European School Survey Project on Alcohol and Other Drugs, 2020. Available: http://espad.org/sites/espad.org/files/2020.3878_EN_04. pdf

24 Centers for Disease Control and Prevention. Youth risk behavior surveillance system (YRBSS), 2020. Available: https://www.cdc.gov/ healthyyouth/data/yrbs/index.htm

$25 \mathrm{Ng} \mathrm{M}$, Micheal K. Thomas Det al. smoking prevalence and cigarette consumption in 187 countries, 1980-2010. JAMA 2014;311:182-92.

26 Looze Mde, Raaijmakers Q, Bogt TT, et al. Decreases in adolescent Weekly alcohol use in Europe and North America: evidence from 28 countries from 2002 to 2010. Eur J Public Health 2015;25 Suppl 2:69-72.

27 Room R, Greenfield TK, Holmes J, et al. Supranational changes in drinking patterns: factors in explanatory models of substantial and parallel social change. Addict Res Theory 2020;28:467-73.

28 Kraus L, Room R, Livingston $\mathrm{M}$, et al. Long waves of consumption or a unique social generation? exploring recent declines in youth drinking. Addict Res Theory 2020;28:183-93.

29 Raitasalo K, Kraus L, Bye EK, et al. Similar countries, similar factors? studying the decline of heavy episodic drinking in adolescents in Finland, Norway and Sweden. Addiction 2021;116:62-71.

30 Docherty G, McNeill A. The hardening hypothesis: does it matter? Tob Control 2012;21:267-8. 
31 Fernández E, Lugo A, Clancy L, et al. Smoking dependence in 18 European countries: hard to maintain the hardening hypothesis. Prev Med 2015;81:314-9.

32 Seo D-C, Huang Y. Systematic review of social network analysis in adolescent cigarette smoking behavior. J Sch Health 2012;82:21-7.

33 Takakura M, Miyagi M, Ueji M, et al. The relative association of collective efficacy in school and neighborhood contexts with adolescent alcohol use. J Epidemiol 2019;29:384-90.

34 Alexander C, Piazza M, Mekos D, et al. Peers, schools, and adolescent cigarette smoking. J Adolesc Health 2001;29:22-30.

35 Ministry of Health, Labour and Welfare of Japan. National health and nutrition survey, 2020. Available: https://www.mhlw.go.jp/bunya/ kenkou/kenkou_eiyou_chousa.html
36 Higuchi S, Matsushita S, Osaki Y. Drinking practices, alcohol policy and prevention programmes in Japan. International Journal of Drug Policy 2006;17:358-66.

37 Umeda M, Oshio T, Fujii M. The impact of the experience of childhood poverty on adult health-risk behaviors in Japan: a mediation analysis. Int J Equity Health 2015;14:145.

38 Bradley BJ, Greene AC. Do health and education agencies in the United States share responsibility for academic achievement and health? A review of 25 years of evidence about the relationship of adolescents' academic achievement and health behaviors. J Adolesc Health 2013;52:523-32.

39 So ES, Park BM. Health behaviors and academic performance among Korean adolescents. Asian Nurs Res 2016;10:123-7. 